\title{
EDITORIAL
}

\section{VETERANS AND SOCIETY}

In 2015, in Athens, a decision was made that the upcoming conference of military historians under the auspices of the Partnership for Peace programme in the Conflict Studies Working Group (CSWG) would be hosted by Slovenia. In cooperation with the Ministry of Defence and with its support we established an organisational committee, consisting of four institutions: the Military Museum in the name of the Ministry of Defence of the Republic of Slovenia, Institute of Contemporary History, Faculty of Social Sciences, and the French Ministry of Defence, represented by the Veterans and War Victims Office. We would like to thank the Minister of Defence Andreja Katič and Brigadier Milko Petek for their assistance with the organisation, financing, and understanding of the role of the Republic of Slovenia in the international scientific community. This understanding and complete support were crucial for the realisation of a successful international consultation, where we managed to confront an overabundance of experiences and present numerous challenges, as well as ensure that all the participants left Ljubljana with plenty of good impressions and new knowledge, also about the Slovenian defence system and our history.

Regarding the selection of topics, which the researchers from more than thirty countries would research and then present at the annual conference, we agreed that this time we would focus on a topic that was not as distinctively military: war veterans. Why veterans? We, military historians, far too often concentrate on important conflicts, battles and wars, where the most important roles are in the hands of military commanders, political decision-makers, and coalitions of forces. With great zeal we study tactics, operations, strategies, and analyse the impact of every possible more or less important factor that influenced either the course of the conflict in question or its results. We analyse and interpret the consequences of engagements, battles and wars by means of various archive materials, revealing layers of secrets involved in what may already be numerous conventional facts... 
However, when the weapons fall silent, as the stage is once again taken over by politicians and as normal life in its myriad of ways resumes (as war and its consequences are undoubtedly abnormal circumstances), the elimination of the consequences of war comes to the forefront. Everyone focuses on the restoration of devastated cities and infrastructure as well as on the revitalisation of state economies. The militaries of the victorious as well as - even more so - the defeated side retreat to the background. Soldiers, perhaps especially those who cannot continue working in the military structures due to the consequences of wars, become even less visible. Precisely these consequences of wars leave permanent scars on the soldiers. They can alter the soldiers' personalities irreversibly and completely, and often change the way of the former soldier's lives forever. Unfortunately it frequently happens that the soldiers' societal, social and general status takes a turn for the worse as well. Precisely for this reason a number of various veteran organisations have been established, whose purpose is not only to maintain contacts between the former soldiers but also to represent them, their status and their rights, and bring the attention to their unequal position in the society. One would expect that the status of veterans would thus be addressed properly and that further potential marginalisation of the former members of the armed forces would no longer be an issue, but unfortunately that is not the case.

Although the attitude of the state towards the veterans in fact reflects its maturity, sensitivity to the vulnerable, and respect of its most meritorious citizens, this issue is often not settled in a manner that one would expect. The reasons for this situation can be found on both sides: on the side of the decision-making elites, which far too eagerly assign top priority to other, possibly more pressing issues; as well as on the side of the veteran organisations themselves, which should certainly operate in such a way as to represent a direct and tougher negotiator when it comes to the status of veterans. During the economic crisis, when the negative consequences almost as a rule affect the lowest social strata most adversely, the situation of the veterans is not much different. The cutbacks of national and consequently defence budgets result in the diminished resources available for the veterans. Most often the veterans are where the financial cuts actually begin.

For this reason the discussion about the status of veterans is a very pressing topic, even today. At the same time the veteran organisations are the ones that represent a live historical memory of extreme efforts and great sacrifice. As such they are a living reminder of what wars and post-war events represent. The decision-makers should learn so much from them... And perhaps these sorts of discussions will contribute to changes in these relations.

Esteemed veterans, we should thank you, pay our respect to you, and endeavour to maintain the sincerest possible relations with you. As it is, it is a fundamental characteristic of every veteran that they have put their nation as a whole before their own interests as well as before the interests of their loved ones and those of other groups. For this noble goal they have been prepared to sacrifice everything: their 
lives. For this reason it is only proper and decent that the highest possible quality of life be ensured for our veterans by means of sincere relations and by including the veterans in all aspects of life in the modern society. 